(C) Elsevier Sequoia S.A., Lausanne - Printed in The Netherlands

\title{
FRICTIONAL BEHAVIOR AND SURFACE FAILURE OF DENTAL FELDSPATHIC PORCELAIN*
}

\author{
G. R. MILLER
}

College of Engineering, University of Michigan, Ann Arbor, Mich. 48104 (U.S.A.)

J. M. POWERS ${ }^{\dagger}$

School of Dentistry, University of Michigan, Ann Arbor, Mich. 48104 (U.S.A.)

K. C. LUDEMA

College of Engineering, University of Michigan, Ann Arbor, Mich. 48104 (U.S.A.)

(Received September 4, 1974)

\section{SUMMARY}

Wear and frictional behavior of dental feldspathic porcelain was investigated in air and in water with a single-pass sliding technique. As-glazed, gold-coated and chromium-coated porcelains were tested. Friction of the as-glazed porcelain was higher in water and surface damage was more extensive than in air. Gold-coating reduced the friction but had no apparent effect on the mode of surface failure in these environments. Chromium-coating did not reduce the friction at higher loads but did reduce the extent of surface damage when compared with the as-glazed material.

\section{INTRODUCTION}

Mechanical properties of non-metallic materials are affected often dramatically by the nature of the testing environment. This is true of wear and frictional behavior also. Westwood and associates ${ }^{1,2}$ have investigated the effect of different liquid environments on fracture and machining properties of soda-lime glass and other nonmetallic materials. Buckley ${ }^{3,4}$ has measured friction caused by single-pass sliding on crystalline ceramics ( $\mathrm{LiF}$ and $\left.\mathrm{CaF}_{2}\right)$ in different surface- active liquid media. Powers, Ludema and Craig $^{5}$ studied the effect of liquids on the friction and mode of surface failure of fluorapatite single crystals. In all of these studies, the testing environment was an important factor affecting wear and frictional behavior.

The purpose of this study is to investigate in a fundamental way the wear and frictional behavior of dental feldspathic porcelain. Porcelains are used in dentistry as esthetic facings in crown and bridge prosthetics and as artificial teeth in complete denture prosthetics. Wear and frictional behavior are of importance clinically because: (1) porcelain restorations cause opposing material in contact with them to

* This investigation was supported by USPHS Research Grant DE-03652 from the National Institute for Dental Research, National Institutes of Health, Bethesda, Maryland 20014 (U.S.A.)

+ All communications should be directed to Dr. Powers. 
wear and to a lesser extent are worn themselves, (2) porcelain restorations frequently must be machined by dental instruments to obtain correct occlusal relationships between upper and lower jaws, and (3) forces caused by frictional resistance of porcelain rubbing against opposing material during chewing and other jaw movements are transmitted to the supporting oral tissues. Koran, Craig and Tillitson ${ }^{6}$ have observed that the coefficient of friction of porcelain rubbing against porcelain was higher in saliva than in air, but the mode of surface failure as influenced by environment was not described. In the present study, dental porcelain in an as-glazed condition was tested by single-pass sliding in air and in distilled water. The effects of gold and chromium coatings on the wear and frictional behavior of porcelain in these environments was evaluated.

\section{MATERIALS AND METHODS}

Rectangular specimens $(2.2 \times 0.6 \times 0.6 \mathrm{~cm})$ of a feldspathic dental porcelain ${ }^{\star}$ were made in a brass mold using $1.7 \mathrm{~g}$ of powder combined with $0.5 \mathrm{ml}$ of distilled water. The prepared paste was vibrated into the mold in layers that were blotted to remove excess water from the surface. The green specimens were allowed to dry for $24 \mathrm{~h}$ prior to firing. Each specimen was fired individually in a vacuum furnace to a biscuit bake (approximately $940^{\circ} \mathrm{C}$ ) at a heating rate of $56^{\circ} \mathrm{C} / \mathrm{min}$. After slowly cooling, each specimen was ground on two opposing sides using 240 grit silicon carbide paper to produce flat test surfaces. Each specimen then was glazed for $30 \mathrm{~s}$ at a temperature of $995^{\circ} \mathrm{C}$ and again slowly cooled.

Twenty-nine specimens were prepared and divided into three groups for wear testing. Thirteen specimens were tested in an as-glazed condition. Ten specimens were coated with a layer ( $200 \AA$ thick) of gold by vapor deposition before testing. Six specimens were coated with chromium by an ion plating process ${ }^{7}$.

The apparatus used in this investigation to scratch the surface of a specimen and measure the tangential force has been described in detail elsewhere ${ }^{8,9}$ but can be described briefly as consisting of the following: surface grinder, loading jig, friction transducer, diamond slider, and sample holder. A diamond hemisphere ( $360 \mu \mathrm{m}$ diam.) was slid across the surface of the porcelain specimens. Ten parallel, one-traversal scratches that resulted from sliding a normal load of 50 to $1000 \mathrm{~g}$ were made on each specimen in environments of air and distilled water. The diamond slider was attached to the loading jig by a strain-gage transducer that allowed the tangential force to be recorded. The specimens were mounted in a holder on the table of surface grinder moving at a speed of $0.025 \mathrm{~cm} / \mathrm{s}$.

Tangential force and track width data were collected for each run. Track width was measured on a metallograph with the use of a calibrated eyepiece. A scanning electron microscope was used to study wear scars further. Wear scars were classified as to the extent of surface damage according to the following scale: ductile failure (Class 1), tensile cracking (Class 3), and chevron formation (Class 5). Damage intermediate to these was classified as Class 2 or Class 4 , respectively. From failure classification data, the maximum normal load above which a ductile mode of failure (Class 1) was no longer observed $(\Omega)$ was chosen. 
Hardness measurements were made on a hardness testing machine with the use of a Knoop indentor. Twenty individual tests were performed on each of five of the as-glazed specimens with ten measurements made in air and ten measurements made with the sample immersed in distilled water.

The effect of normal load in both environments was investigated. The test consisted of allowing the diamond slider mounted in the loading jig to come gently in contact with the surface of the as-glazed specimens. Loads of 600,800 , and 1000 were used. The surface damage that resulted from the application of these normal loads was then studied under a microscope. Francon illumination was used to observe the contact area to determine if recovery of the porcelain was complete after removal of the load.

Statistical analysis of the data was performed with the analysis of variance ${ }^{10}$. The slopes $(\beta)$ of curves of tangential force versus normal load were determined with the use of a linear regression model.

\section{RESULTS}

Average values of tangential force and failure classification in air and in water are plotted as a function of normal load in Figs. 1 to 3 for the as-glazed, gold-coated, and chromium-coated porcelain, respectively. A linear regression line was fitted to the tangential force versus normal load data for each environment. The slope $(\beta)$ of this

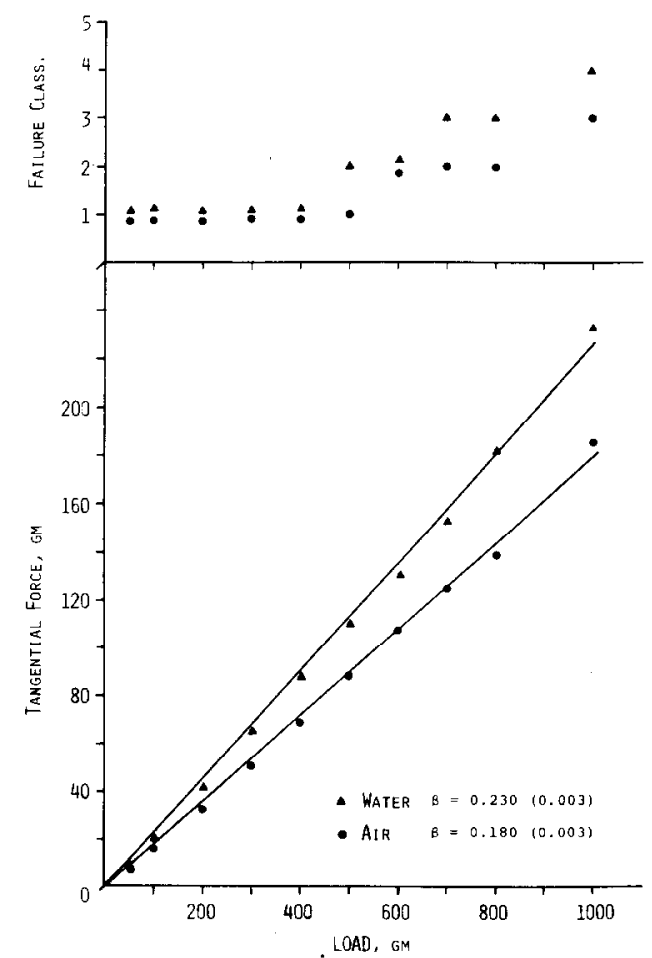

Fig. 1. Effect of normal load on tangential force and failure classification of as-glazed porcelain for sliding in air and in water. 


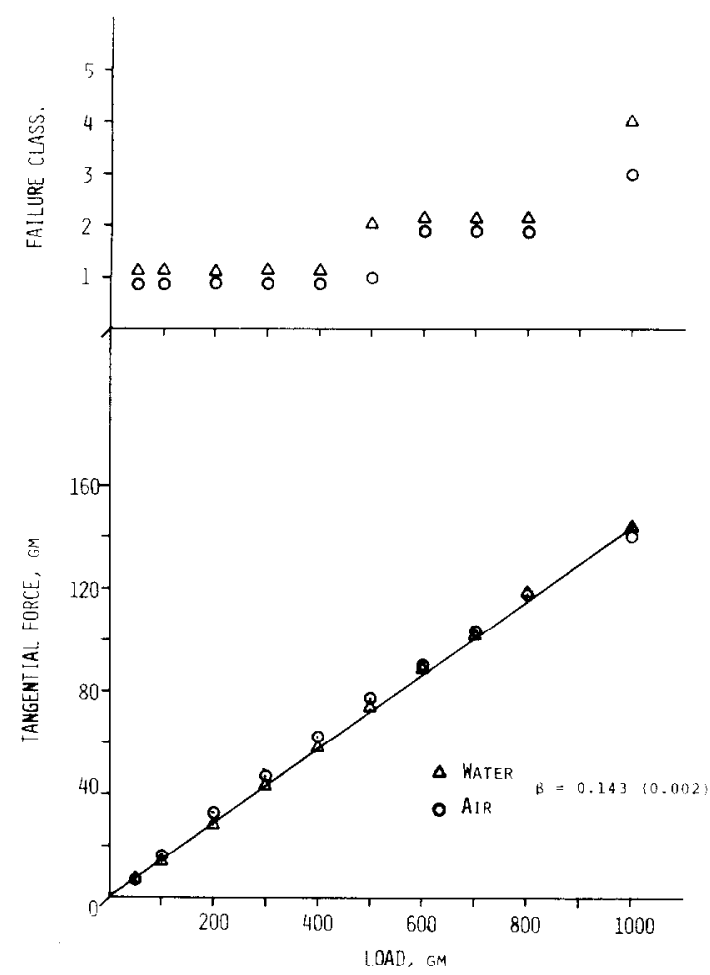

Fig. 2. Effect of normal load on tangential force and failure classification of gold-coated porcelain for sliding in air and in water.

regression line and its standard deviation are indicated on the plot. With the goldcoated and chromium-coated specimens, there were no significant differences between the effects of air and water on the tangential force; therefore, the data were incorporated into one regression line. With the chromium-coated specimens, two regression lines were required to explain the behavior observed above and below the $200 \mathrm{~g}$ normal load. Values of $\beta$ and $\Omega$, the load at which a ductile to brittle transition took place, are summarized in Table I.

The track widths for the as-glazed porcelain in air and in water are plotted as a function of normal load on $\log -\log$ coordinates in Fig. 1. Because there was no significant difference observed between the effect of air and water on track width, one regression line was fitted to the combined data. The measured values of track width also are compared in Fig. 4 with values computed from an equation derived from a special case of Hertz's theory of contact between two elastic spheres. ${ }^{\star}$

Mean values and standard deviations of Knoop Hardness Number (KHN) in air and in water were determined for the as-glazed porcelain. The KHN for porcelain tested in air was 591 with a standard deviation of 73 . The KHN for porcelain tested in

$\star$ The equation used was: $w=1.82(W R)^{\frac{1}{3}}\left[\left(E_{B}\left(1-r_{A}^{2}\right)+E_{A}\left(1-r_{B}^{2}\right)\right\} / E_{A} E_{B}\right]^{\frac{1}{3}}$, where $w$ equals track width, $W$ equals normal load, $R$ equals the radius of the diamond hemisphere, and $\because$ and $E$ are the Poisson's ratio and Young's modulus of porcelain $(A)$ and diamond $(B)$, respectively. In this equation Poisson's ratio and Young's modulus for diamond were 0.30 and $930 \mathrm{GN} / \mathrm{m}^{2}$, respectivcly. Poisson's ratio and Young's modulus for porcelain were 0.24 and $74 \mathrm{GN} / \mathrm{m}^{2}$, respectively. 


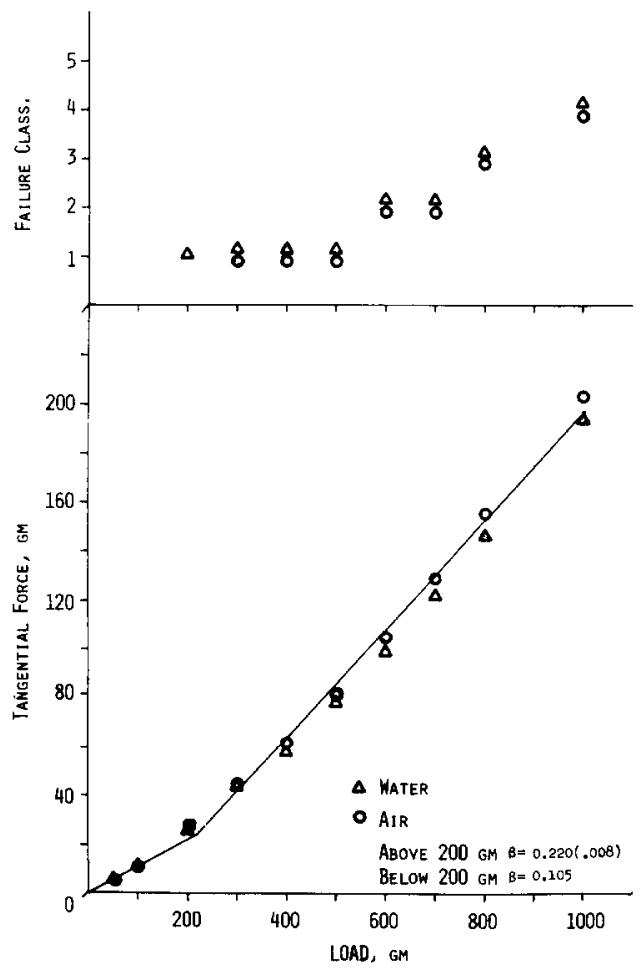

Fig. 3. Effect of normal load on tangential force and failure classification of chromium-coated porcelain for sliding in air and in water.

TABLE I

EFFECT OF ENVIRONMENT ON $\beta$ AND $\Omega$ FOR AS-GLAZED, GOLD-COATED, AND CHROMIUM-COATED PORCELAINS

\begin{tabular}{llll}
\hline Preparation & Environment & $\beta^{\star}$ & $\Omega(g)$ \\
\hline As-glazed & Air & $0.181(0.003)$ & 600 \\
& Water & $0.227(0.003)$ & 500 \\
Gold-coated & Air & $0.143(0.002)$ & 600 \\
& Water & & 500 \\
Chromium-coated & Air & $0.105^{+}$ & 600 \\
& Water & $0.220(0.008)^{\dagger}$ &
\end{tabular}

* Mean with standard deviation in parentheses.

+ Mean value for both environments with loads below $200 \mathrm{~g}$.

$\uparrow$ Mean value for both environments with loads above $200 \mathrm{~g}$.

water was 625 with a standard deviation of 54 . The difference between the KHN in air and in water was significant statistically.

Photomicrographs of surface failure typical of that observed for the as-glazed, gold-coated, and chromium-coated porcelain are shown in Figs. 5 and 6. The change in 


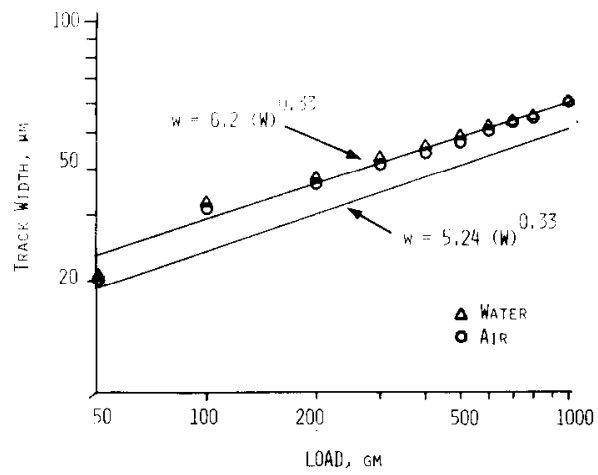

Fig. 4. Effect of normal load on track width of as-glazed porcelain for sliding in air and in water.
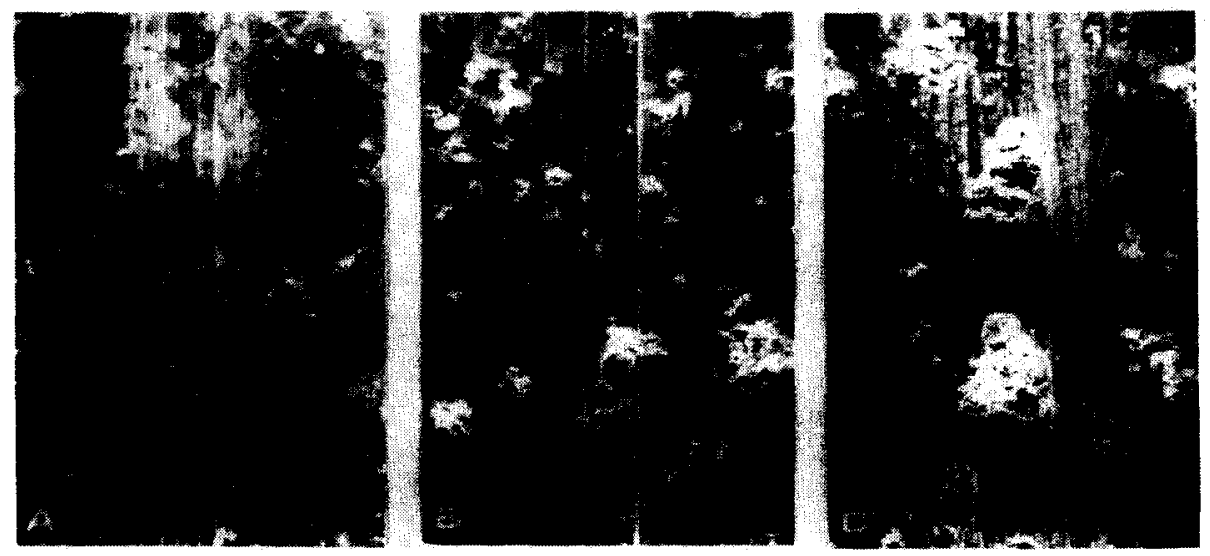

Fig. 5. Surface failure of as-glazed porcelain for sliding in water. (A) Class 1, (B) Class 2, and (C) Class 4.

classification of surface failure with increasing normal load is shown in Fig. 5 for an as-glazed porcelain sample tested in water. A Class 1 failure is shown in Fig. 5(A), Class 2 in Fig. 5(B), and Class 4 in Fig. 5(C). Figures 6(A) and 6(B) compare the surface failure of as-glazed porcelain when tested in air and in water at a normal load of $600 \mathrm{~g}$. The increased surface damage of the porcelain when tested in water is evident. Figure 6(C) shows the surface failure of gold-coated porcelain tested in air at a normal load of $600 \mathrm{~g}$. For all the normal loads tested, the gold was removed completely from the wear track as shown in this example. Figure 6(D) shows the surface failure of chromium-coated porcelain tested in water at a normal load of $600 \mathrm{~g}$. A bove a normal load of $200 \mathrm{~g}$, the coating remained in the wear track but was removed along the periphery of the wear track as shown in this example. Below a normal load of $200 \mathrm{~g}$, however, the coating remained completely intact on the porcelain.

The application of a normal load without tangential motion to as-glazed porcelain resulted in the formation of circular cracks once a critical load was reached. In air no cracks were observed at a normal load of 600 g. (Fig. 7(A)); in water, however, cracking occurred (Fig. $7(\mathrm{C})$ ). The nature of the cracks that occurred at a normal load of $1000 \mathrm{~g}$ is shown in Figs. 7(B) and 7(D) for the as-glazed porcelain tested in air and 

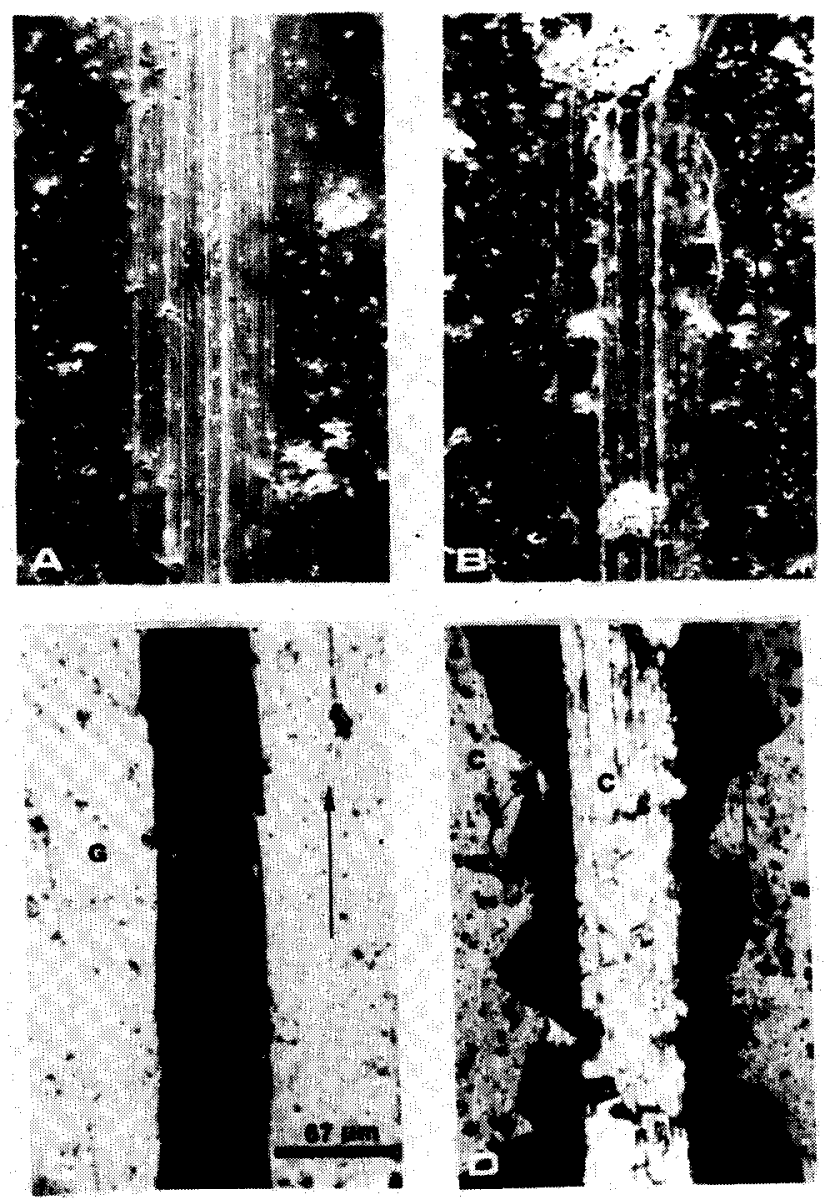

Fig. 6. Surface failure of porcelains at a normal load of $600 \mathrm{~g}$. for sliding. (A) As-glazed tested in air, (B) Asglazed tested in water, (C) Gold-coated tested in air, and (D) Chromium-coated tested in water.

in water, respectively. It was observed in these cases that recovery of the indentation was complete.

\section{DISCUSSION}

The single-pass wear test employed in this study reveals that environment is an important factor in the wear and frictional behavior of dental porcelain. It was shown that a significantly higher tangential force was produced on as-glazed porcelain for sliding in bulk water as contrasted to sliding in air. It was evident that greater surface damage occurred for sliding in bulk water. It is proposed that the cracking of the as̀-glazed porcelain during sliding is a result of Hertzian elastic stresses caused by the normal load. The photomicrographs in Fig. 7 show that the application of a normal load, without an applied tangential force, produces Hertzian crack rings in the porcelain and that cracking takes place at a lower normal load under bulk water. 

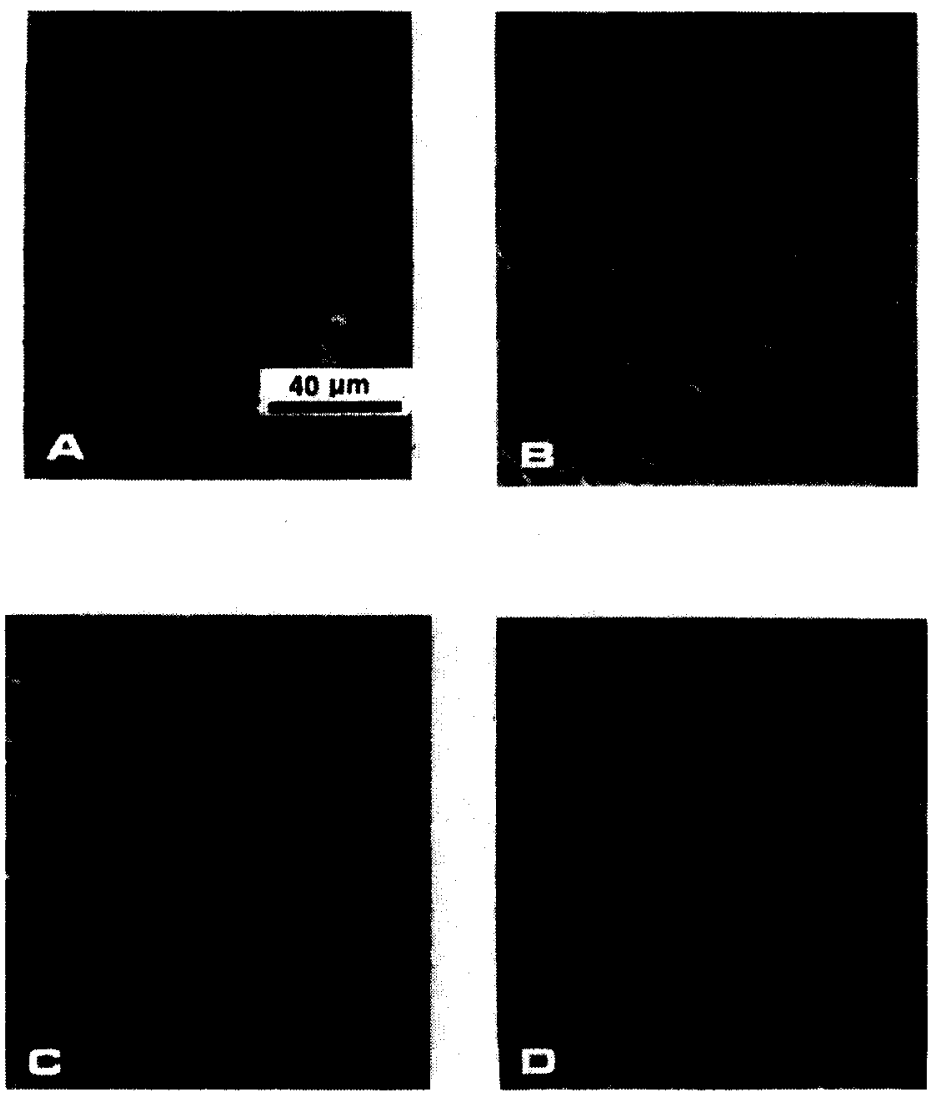

Fig. 7. Formation of circular cracks in as-glazed porcelain when loaded normally without sliding.

Sherrill and $\mathrm{O}^{\prime} B \mathrm{Brien}^{11}$ found that water significantly reducud the transverse strength of dental porcelain.

If the adhesion forces between the porcelain and the diamond slider are considered negligible, then the major portion of the tangential force is a result of the deformation of the porcelain. Three types of deformation can occur : elastic and plastic deformation and cracking. The as-glazed porcelain behaved elastically for the most part over the load range studied. The track width was found to be proportional to $\mathrm{W}^{\frac{1}{3}}$ and was thus in agreement with the behavior predicted by Hertzian theory for clastic deformation. Also, after the normal load alone was applied and removed, there was no discernible difference between the surface level of the area of contact and the surroundings. Thus the majority of deformation, due to application of the load, reverses itself elastically upon removal of the normal load. Although the bulk of the deformation is elastic, another component of friction is energy lost due to plastic deformation as manifested by tiny grooves formed within the wear track. These small grooves are plowed out by asperities on the surface of the diamond slider.

During sliding, the porcelain is elastically deformed and then recovers when the slider moves on. Upon elastic recovery, energy is returned to the slider. When cracking occurs elastic energy is used to create new surfaces. This energy is subtracted 
from the elastic energy that would be returned to the slider, and therefore, results in an increase in tangential force.

It follows that an environment that facilitates cracking should also bring about an increase in tangential force when compared with an environment that does not produce cracks as readily. The tests run in bulk water, which facilitated cracking, produced a significantly higher tangential force. There were no observed surface cracks for the as-glazed porcelain in air or in water below $500 \mathrm{~g}$; however, subsurface cracks can form below this load and would explain the higher value of $\beta$ measured in water below $500 \mathrm{~g}$.

With a metallic coating on the surface of the porcelain, there was no apparent effect of environment on $\beta$. A gold film deposited on the surface produced the lowest $\beta$ in both wet and dry environments. The tangential force is a combination of the forces required to remove the gold from the porcelain and to deform the gold plastically. Because the gold bonds very weakly to the porcelain and has a low shear strength, the tangential force is low in this case.

Chromium, ${ }^{\star}$ which was ion plated on the porcelain surface, exhibits more tenacious bonding to the porcelain than gold. Two distinct regions of behavior were observed with a transition occurring at $200 \mathrm{~g}$. In the first region, for loads less than $200 \mathrm{~g}$, no deformation of the porcelain was observed and the chromium coating remained intact. The value of $\beta$ in this region was low $(0.105)$. At loads above $200 \mathrm{~g}$, $\beta$ was roughly twice as high $(0.22)$. There was a change in the mode of deformation of the chromium-coating with increased load. Some of the chromium was removed from the porcelain along the sides of the contact area. This added deformation may account for the increase in $\beta$.

The gold- and chromium-coated porcelains exhibited different surface failure in the two environments. With the gold-coating, the transition load $(\Omega)$ was lower in water than in air. The classification of surface failure varied with normal load in a manner similar to that of the as-glazed porcelain. During sliding, the gold-coating was pushed up ahead of the slider. This allowed bulk water to contact the surface before the slider passed over it. 'Thus, the gold-coating reduces the tangential force caused by sliding but does not affect the mode of surface failure. This is further evidence that cracking is dependent upon normal load and environment, but not upon tangential force.

There were no observed differences in values of $\beta$ or $\Omega$ for the chromium-coated porcelain when tested in air or in water. The transition load $(\Omega)$ was the same, $600 \mathrm{~g}$, for both environments and was the same as for the other porcelains tested in air. It appears that the chromium-coating prevents the bulk water (which facilitates cracking) from reaching the surface. This produces surface and subsurface failure behavior similar to that of the specimens run in air.

\section{CONCLUSIONS}

A single-pass test was used to study the frictional behavior and surface failure of a dental feldspathic porcelain. The deformation of the porcelain during sliding was

* The chromium-coating probably was a chromium oxide, but will be referred to as a chromiumcoating. 
explained with Hertzian elastic theory. It was shown that cracking of the porcelain was a result of elastic stresses caused by the application of a normal load and not by the tangential force. Bulk water was observed to facilitate cracking and increase $\beta$ of the as-glazed porcelain compared with air. The larger value of $\beta$ encountered with bulk water was attributed to increased cracking which reduced the amount of recoverable elastic strain energy, energy that would have been returned to the slider.

Gold and chromium coatings on the porcelain surface made $\beta$ independent of the environment. Surface damage was greater in water for porcelain with a gold coating, apparently because the gold was removed allowing water to cover the surface. The chromium-coating remained intact within the area of contact in the wear track and the surface damage was not affected by the presence of bulk water.

\section{ACKNOWLEDGEMENTS}

The technical assistance of Talivaldis Spalvins, Lewis Research Center, Cleveland, Ohio, is gratefully acknowledged.

\section{REFERENCES}

1 A. R. C. Westwood, G. H. Parr Jr. and R. M. Latanision, Adsorption-sensitive Mechanical and Machining Behaviour of Soda-lime Glass, Martin Marietta Corporation, Baltimore, September, 1970.

2 A. R. C. Westwood and R. M. Latanision, Environment-sensitive machining behavior of non-metals, RIAS Technical Report 70-10c, Martin Marietta Corporation, Baltimore, October, 1970.

3 D. H. Buckley, Influence of surface active agents on friction, deformation and fracture of lithium fluoride, NASA TN D-4716, 1968.

4 D. H. Buckley, Effect of surface active media on friction, deformation and fracture of calcium fluoride. NASA TN D-5580, 1969.

5 J. M. Powers, K. C. Ludema and R. G. Craig, Wear of fluorapatite single crystals: V. Influence of environment of frictional behavior and surface failure, J. Dent. Res., 52 (1973) 1026-1031.

6 A. Koran, R. G. Craig and E. W. Tillitson, Coefficient of friction of prosthetic tooth materials, J. Prosth. Dent., 27 (3) (1972) 269-274.

7 T. Spalvins, Bonding of metal lubricant films by ion plating, NASA TM X-52859, 1970.

8 J. M. Powers and R. G. Craig, Wear of fluorapatite single crystals: I. A method for quantitative evaluation of wear, J. Dent. Res., 51(1) (1972) 168-176.

9 J. M. Powers and R. G. Craig, Wear of fluorapatite single crystals : II. Frictional behavior, J. Dent. Res., $51(2)(1972) 605-610$.

10 D. Fox and K. Guire, Midas, Statistical Research Laboratory, University of Michigan, Ann Arbor, 1972.

11 C. A. Sherrill and W. J. O'Brien, Transverse strength of aluminous and feldspathic porcelain, J. Dent. Res., 53(3) (1974) 683-690. 